\title{
Yoğun Bakımda Kardiyopulmoner Monitorizasyonda Günlük Pratiğimizde "Yeni" Bir Araç: Transtorasik Ekokardiyografi ve Akciğer Ultrasonu
}

\author{
A "New" Tool For Cardiopulmonary Monitorization in Icu in Daily Practice: \\ Transthoracic Echocardiography and Lung Ultrasound
}

\author{
Gülay Eren, Oya Hergünsel, Zafer Çukurova, Yüksel Doğan*, Osman Karakaya* \\ Bakırköy Dr. Sadi Konuk Eğitim Araştırma Hastanesi, Anesteziyoloji ve Reanimasyon Kliniği, Istanbul, Türkiye \\ *Bakırköy Dr. Sadi Konuk Eğitim Araştırma Hastanesi, Kardiyoloji Kliniği, Istanbul, Türkiye
}

\section{ÖZET}

Amaç: Transtorasik ekokardiyografinin ve akciğer ultrasonografisinin yoğun bakımda hasta monitorizasyonunda ve tedavinin takibinde kullanılabileceği hipotezini kanıtlamak üzere deneyimlerimizi gözden geçirmeyi amaçladık.

Gereç ve Yöntem: Yoğun bakım doktoru tarafından 18 hastaya transtorasik ekokardiyografi (TTE) yapılmış ve bu ekokardiyografik değerlendirmeler, bir kardiyolog tarafindan imaj kalitesi ve güvenilirlik açısından değerlendirilmiştir. Hastaların demografik özellikleri, klinik problemleri, prognozları, kullanılan akustik pencere, ekokardiyografik bulguları ve bulguların klinik progrese katkısı dörtlü bir skala değerlendirmesiyle kayıt edilmiştir.

Bulgular: 18 hastaya 21 TTE ve iki akciğer ultrason değerlendirmesi yapılmıştır. Bu görüntüleme vakaların \%94,3'ünde yeterli ve değerli veri sağlamıştır. \%38,8 vakada TTE mevcut bilgileri destekler nitelikte değerlendirilirken, \%33,3'ünde yeni bilgi ve \%22,2'sinde de tanıyı tamamlayan ve definitif tedaviye götüren bilgi ve katkı sağlamıştır. Kayıt edilen TTE görüntüleri kardiyolog tarafından skorlanmış ve hiçbir hastada görüntü kalitesi değerlendirilemez olarak belirlenmemiştir. Iki hastada da akciğer ultrasonografisi tedaviyi yönlendirmede değerli bilgi sağlamıştır.

Sonuç: Ultrasonografi (TTE ve akciğer) yoğun bakımda yatakbaşı monitorizasyonda kritik hastanın takip ve tedavisine katkı sağlayabilecek ve etkin bir şekilde kullanılabilecek noninvazif bir araçtır. (Türk Yoğun Bakım Derneği Dergisi 2012; 10: 13-9)

Anahtar Kelimeler: Yoğun bakım, kardiyopulmoner monitorizasyon, ekokardiyografi, ultrason

\section{Sunulduğu Kongre: 2010 15.Ulusal Yoğun Bakım Kongresi (bir bölümü)}

Yazışma Adresi/Address for Correspondence: Dr. Gülay Eren, Bakırköy Dr Sadi Konuk Eğitim Araştırma Hastanesi, Anesteziyoloji ve Reanimasyon, Istanbul, Türkiye Tel.: +90 2124147141 Faks: +90 3122237333 E-posta: glyaeren@gmail.com Geliş Tarihi/Received: 09.10.2011 Kabul Tarihi/Accepted: 30.03 .2012

Türk Yoğun Bakım Derneği Dergisi, Galenos Yayınevi tarafından basılmıştır. / Journal of the Turkish Society of Intensive Care, published by Galenos Publishing.

\section{SUMMARY}

Objective: We aim at looking over our experiences in order to prove the use of transthoracic echocardiography and lung ultrasonography for monitorization of treatment of patients in intensive care.

Material and Method: 18 patients in intensive care unit were examined echocardiographically by an intensivist and a cardiologist evaluated these transthoracic echocardiography (TTE) visions for image quality and reliability. Demographic and clinical data of patients, clinical prognosis, acustic windows used for imaging, echocardiographical findings and contribution of these findings to clinical progress evaluated by a 4-scale all were recorded and evaluated.baseline within 72 hours after administration of contrast agent.

Results: 18 patients were evaluated by 21 TTE images and 2 lung ultrasonography. This imaging provided adequate and valuable data for $94.3 \%$ of cases. In $38.8 \%$ of cases TTE images were supportive for the present data, whereas it provided new data in 33.3\% and data contributing the diagnosis and leading to definitive treatment in $22.2 \%$. Recorded TTE images were scored by the cardiologist and none of them were evaluated as imaging quality unevaluable. Both lung ultrasounds provided valuable data to the management of patients. Conclusion: Ultrasonography (both TTE and lung ultrasound) is a safe, noninvasive bedside tool to provide valuable contribution to the management of critical cases in intensive care unit. (Journal of the Turkish Society Intensive Care 2012; 10: 13-9)

Key Words: Intensive care, cardiopulmonary monitorization, echocardiography, ultrasound

\footnotetext{
ISNN: 1300-5804
ISN
} 


\section{Giriş}

Yatakbaşı ultrasonla görüntüleme, kritik hastada tanıyı belirleme ve tedaviyi yönlendirmede son yıllarda hem acil tıp hekimleri hem de yoğun bakımcıların kullandığı önemli bir araç olmuştur. Zira kritik hastada ultrasonografi, bazı durumlarda invazif hemodinamik monitorizasyonun katkısından daha değerli ve en azından, daha hızlı değerlendirme şansı verir. Son on yılda yatakbaşı ultrasonografi yoğun bakımlarda santral kateterizasyonlardan hastanın kardiyak performansının değerlendirilmesi, global sIVI dengesinin takibi ve pnömotoraks, plevral efüzyon, atelektazi gibi birçok pulmoner patolojinin tanı ve takibinde etkin bir şekilde kullanımaya başlanmıştır $(1,2)$.

Yoğun bakımlarda hemodinamik açıdan stabil olmayan hastalarda monitorizasyon ve tedavi çoğunlukla zordur ve rasyonel, problem-hedefli bir yaklaşım gerektirir. Kalbin ikiboyutlu görüntülemesi, hemodinamik belirleyicilerin ortaya çıkarımasında ve bozukluğun nedenlerini hızlı bir şekilde dışlama veya doğrulamada kullanılabilecek noninvazif, basit bir yöntemdir. Dolayısıyla, ultrasonografi, şu an kalbin yatakbaşı gerçek zamanlı ve dinamik görüntülenmesini sağlayan tek yoldur. Bu yolla, kalp, büyük damarlar ve plevra görüntülenerek kardiyak morfoloji, sistolik ve diastolik fonksiyonu ve belirgin patolojiler hakkında hızlı ve noninvazif değerlendirme yapılabilir $(3,4)$. Kalbin duvar kalınlıkları ve kavite genişlikleri ölçülerek önyük, ardyük ve kontraktilite gibi hemodinamik belirleyiciler kolaylıkla görüntülenebilir ve böylece hızı bir şekilde terapötik kararlar alınıp tedaviye cevap da tekrarlanan görüntülemelerle monitorize edilebilir. Bu çalışmayla, biz de yoğun bakım ünitemizde yeni uygulamaya başladığımı transtorasik ekokardiyografinin (TTE) ve akciğer ultrasonografisinin hasta monitorizasyonunda ve tedavinin takibinde kullanılabileceği hipotezi ile deneyimlerimizi gözden geçirmeyi amaçladık.

\section{Gereç ve Yöntem}

Eylül 2009 ve Mayıs 2010 tarihleri arasında yoğun bakım ünitemizde tedavi olan, sedasyon altında mekanik ventilasyon desteğindeki hastalardan rutin monitorizasyon yöntemleriyle yönlendirilmiş kardiyopulmoner değerlendirmelere göre planlanmış tedaviyle klinik gelişme sağlanamayan hastaların TTE protokolüyle değerlendirmeleri ileriye dönük olarak incelenmiştir. TTE uygulaması, yurtdışında TTE kullanımıyla ilgili iki çalıştay (ESA 2008 Kopenhag ve ESA 2009 Milano) ve bir sertifika programı (Neapean Institute Critical Care Echo Course 2009, Sidney) eğitimlerine katılış bir yoğun bakım doktoru tarafından yapılmıştır. Daha sonra bu ekokardiyografik değerlendirmeler, bir kardiyolog tarafından imaj kalitesi ve güvenilirlik açısından değerlendirilmiştir. Hastaların demografik özellikleri, klinik problemleri, prognozları, kullanılan akustik pencere, ekokardiyografik bulguları (Tablo 1) ve bulguların klinik progrese katkısı dörtlü bir skala değerlendirmesiyle kayıt edilmiştir.

\section{Ekokardiyografik Teknik}

Eko değerlendirmeleri için yoğun bakımda bulunan LOGIQ-e, GE Healthcare marka ultrason ve 3MHz kardiyak sektör prob (GE Medical Systems, Phoenix-USA) kullanılmıştır. TTE uygulaması sırtüstü pozisyonda yapıImışıır, suboptimal görüntü alındığı durumlarda hasta sol yanına yatııılarak görüntüleme tekrarlanmıştır. TTE görüntülemesi 4 standart pencereden yapılmıştır (Şekil 1):
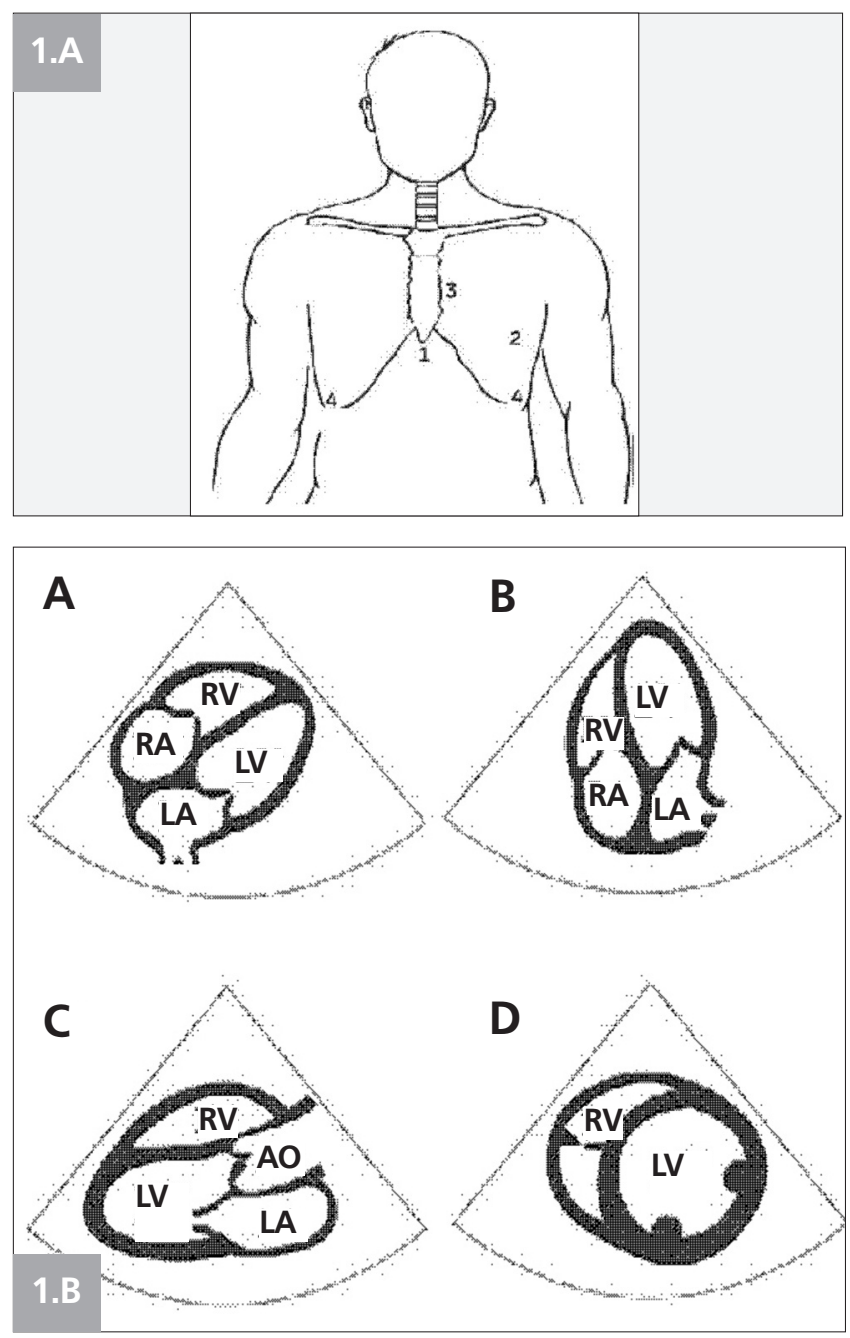

Şekil 1. FATE protokolü: a) Ultrason probunun pozisyonu, 1: subkostal pencere, 2: apikal pencere, 3: parasternal pencere, 4: plevral pencere; b) TTE esnasında ekranda görülen dört önemli imaj planının şematik görüntüsü, A) subkostal 4-boşluk görüntüsü [pozisyon 1], B) apikal 4boşluk görüntüsü [pozisyon 2], C) parasternal uzun aks görüntüsü [pozisyon 3] ve D) parasternal kısa aks görüntüsü [pozisyon 3]. AO: Aorta, LA: sol atrium, RA: sağ atrium, LV: sol ventrikül, RV: sağ atrium. ( Alıntı yapılan kitap: Irwin RS, Rippe JM. Intensive Care Medicine. 6th edition, LWW, Philadelphia, USA, 2008, Echocardiography in the Intensive Care Unit, Chapter 29, pp, 290-301.) 
1. Subkostal Pencere: Prob sağ kostal kurvatürün altına yerleştirilip ultrason imaj planı kalbe yönlendirilerek alınmıştır (subkostal 4-boşluk görüntüsü).

2. Apikal Pencere: Prob kalbin apeksinin üstüne yerleştirilmiştir (apikal 4- boşluk görüntüsü).

3. Parasternal Pencere: Prob, apeksi sağ klavikulanın orta noktasını birleştiren çizgide sternumun sol kenarına konarak alınmıştır (parasternal uzun aks görüntüsü).

4. Plevral pencere: Prob her iki göğüs duvarının lateraline ön aksiler çizgi üzerine konur.

TTE değerlendirmesi FATE (Focus Assessed Transtorasik Echocardiography) protokolüne $(5,6)$ uygun olarak yapılmıştır. Bu protokolün amacı basitçe, belirgin kardiyak patolojilerin görüntülenmesi, kalbin duvar kalınlıklarının ve boşlukların genişliklerinin değerlendirilip kontraktilitesinin değerlendirilmesi ve hastanın SIVı durumunun belirlenmesidir. TTE değerlendirmesi her hastada bütün pencerelerden alınan görüntülerle yapılmış ve gereğinde $\mathrm{M}$-mode ve Doppler modaliteleri (valvular patolojiler ve kardiyak debi değerlendirmesi için) uygulanmıştır. Görüntüler kayıt edilmiş ve ardından bir kardiyolog tarafından imaj kalitesi ve güvenilirlik açısından gözden geçirilmiştir ve 5 basamaklı bir skorla (5: mükemmel görüntü, 4: iyi kalitede görüntü, 3: orta kalitede, 2: kabul edilebilir görüntü, 1: değerlendirilemez görüntü) değerlendirilmiştir. Akciğerin ultrasonografik değerlendirilmesi gerektiği durumlarda bu değerlendirme
BLUE protokolüne (7) göre yapılmıştır. Veri değerlendirmeleri sayısal, ortalama ve yüzde olarak verilmişsir.

\section{Bulgular}

Hastaların demografik verileri ve değerlendirmeleri Tablo 1'de özetlenmiştir. Bu dönemde yoğun bakımda tedavisi gereken 18 hastada 21 kez TTE, bunlardan ikisinde ayrıca FATE dışında BLUE protokolüne (7) göre akciğer ultrasonografi değerlendirmesi yapıldı. Bütün hastalar TTE uygulaması esnasında sedoanaljezi altında mekanik ventilasyon (kontrole solunumda ortalama $8 \mathrm{ml} / \mathrm{kg}$ tidal volum ve 5-14 $\mathrm{cmH}_{2} \mathrm{O}$ PEEP ile, Tablo 1) desteğindeydi ve 14 hastada görüntüleme sırtüstü pozisyonda, diğer dördünde de sol lateral pozisyonda yapıldı. Biri hariç bütün hastalardan tüm pencere görüntüleri kaydedildi, ancak bir hastada pozisyon değişikliğine rağmen diğer pencerelerden optimal görüntü alınamamış ve hasta sadece subkostal pencereden alınan görüntü ile değerlendirilmiştir. TTE görüntülemesi sonrasında yapılan değerlendirme 7 hastada (örnek: Vaka 2, Tablo 3) tanıya yönelik tedaviyi doğrulamıştır (skor 2, Tablo 2), 6 hastada ise mevcut tedaviyi değiştirmeye yönelik veri sağlanmıştır (skor 3, Tablo 2). Dört hastada (örnek: Vaka 3, Tablo 3) da TTE değerlendirmesinde elde edilen veriler ön tanıyı desteklememiş ve hastanın tedavisini

\section{Tablo 1. Hastaların demografik özellikleri ve klinik tabloları}

\begin{tabular}{|c|c|c|c|c|}
\hline Tanı & Pnömoni/sepsis/ARDS & Kalp yetersizliği & Pulmoner emboli & Postop (non-kardiyak cerrahi) \\
\hline Yaş (yıl) & $24-76$ & $40-81$ & 78 & $55-83$ \\
\hline Hasta sayısı (n) & 6 & 8 & 1 & 3 \\
\hline TTE (n) & 8 & 9 & 1 & 3 \\
\hline Akc USG (n) & 1 & - & - & 1 \\
\hline $\operatorname{PEEP}\left(\mathrm{cmH}_{2} \mathrm{O}\right)$ (ort) & $8,66(6-14)$ & $6,62(5-10)$ & 8 & $7,33(6-9)$ \\
\hline $\mathrm{pH}$ (ort) & 7,39 & 7,41 & 7,43 & 7,40 \\
\hline $\mathrm{PaCO}_{2}(\mathrm{mmHg})$ (ort) & 46,9 & 42,8 & 35,7 & 40,2 \\
\hline $\begin{array}{l}\mathrm{PaO}_{2}(\mathrm{mmHg}) \text { (ort) } \\
\text { inotrop destek }\end{array}$ & 78,8 & 92,6 & 84 & 86 \\
\hline TTE öncesi mevcut & 4 & 6 & - & 1 \\
\hline TTE sonrası kesilen & 1 & - & - & - \\
\hline TTE sonrası eklenen & 1 & 2 & 1 & 1 \\
\hline \multicolumn{5}{|l|}{ SIvı tedavisi } \\
\hline artırıldı & 2 & - & - & 1 \\
\hline azaltıldı & 2 & 2 & 1 & - \\
\hline TTE sonrası & 3 & 1 & - & - \\
\hline \multicolumn{5}{|l|}{ hemofiltrasyon } \\
\hline Prognoz (Sağ/ölüm) & $3 / 3$ & $5 / 3$ & $1 /-$ & $3 /-$ \\
\hline
\end{tabular}

TTE: transtorasik ekokardiyografi, Akc USG: akciğer ultrasonografisi, PEEP: pozitif ekspirasyon sonu basınç 
Tablo 2. Ekokardiyografik bulguların klinik progrese katkısının TTE uygulayıcısı tarafından skorlaması

\begin{tabular}{lll} 
Skor & Açıklama & Hasta sayısı $\mathbf{( n , \% )}$ \\
\hline 1 & Değersiz/yetersiz katkı & $1(\% 5,7)$ \\
2 & Mevcut bilgileri destekleyen bulgu & $7(\% 38,8)$ \\
3 & Yeni bilgi/katkı & $6(\% 33,3)$ \\
4 & Tanıyı tamamlayan ve definitif tedaviye götüren bilgi/katkı & $4(\% 22,2)$ \\
\hline
\end{tabular}

\section{Tablo 3. Örnek hasta değerlendirmeleri}

\begin{tabular}{|c|c|c|c|c|c|}
\hline Vaka & Yaş/cins & YBU yatış sebebi & Tedavi ve Klinik & TTE değerlendirmesi & Progres \\
\hline Hasta 1 & $24 / E$ & Pnomoni/sepsis & $\begin{array}{l}\text { Arrest sonrası } \\
\text { hipotansiyon için inotropi }\end{array}$ & $\begin{array}{l}\text { Hiperkinetik ventriküller, } \\
\text { düşük IVCd, kollapsibilite } \\
\text { indeksi >\%50 }\end{array}$ & $\begin{array}{l}\text { İnotrop destek kesilip } \\
\text { sIvı tedavisi }\end{array}$ \\
\hline Hasta 2 & $49 / E$ & Akut kolanjit/CPR & $\begin{array}{l}\text { Sıvı yüklemesi ve } \\
\text { inotropik tedavi }\end{array}$ & Dilate kardiyomyopati & $\begin{array}{l}\text { İnotropik destek } \\
\text { tedavisinin devamı }\end{array}$ \\
\hline Hasta 3 & $78 / E$ & Pulmoner emboli & $\begin{array}{l}\text { D-dimer yüksek, toraks CTde } \\
\text { emboli? Clexane } 2 \times 0.8 \mathrm{ml}\end{array}$ & $\begin{array}{l}\text { TY yok, sağ ventrikül normal, } \\
\text { global duvar hareketleri hipokinetik }\end{array}$ & $\begin{array}{l}\text { İnotropik tedavi, SIVI } \\
\text { kısıtlaması }\end{array}$ \\
\hline Hasta 4 & $29 / E$ & $\begin{array}{l}\text { Pnömoni/sepsis/ } \\
\text { ARDS }\end{array}$ & Hipotansiyon için sıvı yüklemesi & $\begin{array}{l}\text { CVP:17 olan hastanın septal ve } \\
\text { apikal duvar hareketleri hipokinetik }\end{array}$ & $\begin{array}{l}\text { Sıvı kısıtlaması, } \\
\text { hemodiyafiltrasyon, } \\
\text { inotropik tedavi } \\
\text { başlandı }\end{array}$ \\
\hline Hasta 5 & $83 / K$ & $\begin{array}{l}\text { (Opere PKP) } \\
\text { GiS kanama } \\
\text { solunum sıkıntısı }\end{array}$ & $\begin{array}{l}\text { mekanik ventilasyon } \\
\left(\mathrm{SpO}_{2}<85\right)\end{array}$ & $\begin{array}{l}\text { PA Akc grafi teknik sebeplerle } \\
\text { çekilemedi. Akciğer USG ile } \\
\text { pnömotoraks ekarte edildi }\end{array}$ & $\begin{array}{l}\text { Yüksek PEEP uygulaması } \\
\text { ve uygun pozisyonla } \\
\text { atelektazi düzeltildi, } \\
1 \text { saat sonra } \\
\mathrm{SpO}_{2}>93 \text { oldu }\end{array}$ \\
\hline
\end{tabular}

YBU: yoğun bakım ünitesi, CPR: kardiyopulmoner resüsitasyon, ARDS: akut respiratuar distres sendromu, CVP: santral venöz basınç, PKP: parsiyel kalça protezi, PEEP: pozitif ekspirasyon sonu basınç, IVCd: inferior vena cava çapı, subkostal pencerede ölçüldü, $1.46 \mathrm{~cm}$ (normal:<2.1 cm), TY: triküspid yetersizlik apikal 4-boşluk penceresinde görüntülendi

\section{Tablo 4. TTE görüntülerinin kalite açısından kardiyolog}

tarafından değerlendirmesi

\begin{tabular}{lc} 
TTE uygulaması [ $\mathbf{n}(\%)$ ] & Skor \\
\hline 0 & 5 \\
$14(66,6)$ & 4 \\
$5(23.8)$ & 3 \\
$2(9.6)$ & 2 \\
0 & 1 \\
\hline 5: mükemmel görüntü, 4: iyi kalitede, 3: orta kaliteli, 2: kabul edilebilir görüntü \\
kalitesi, 1: değerlendirilemez görüntü
\end{tabular}

değiştirerek kliniğinde sağlanan gelişme ile ön tanıyı ekarte ettirmiştir (skor 4, Tablo 2). Bir hastada ise TTE değerlendirmesi mevcut duruma bir katkı sağlamamış ve skor 1 olarak nitelendirilmiştir (Tablo 2). Başka bir hastada ise (Vaka 5, Tablo 3) hastanın kliniği kardiyak ultrason değerlendirmesiyle açıklanamayınca ve teknik nedenlerle diğer görüntüleme yöntemleriyle değerlendirilemeyince yapılan pulmoner ultrasonografi ile olası sebepler ekarte edilip tedaviyi planmaya yönelik veri sağlanmıştır.
Kayıt edilen TTE görüntüleri kardiyolog tarafından skorlanmış ve hiçbir hastada görüntü kalitesi değerlendirilemez (skor 1) olarak belirlenmemiştir (Tablo 4). Aşağıda değerlendirilen tüm hastalar içinden örnekleme amacıyla 5 vakaya ait değerlendirmeler kısaca sunulmuştur:

Vaka 1: 24 yaşında erkek hasta yüksek ateş ve solunum sıkıntısı ile hastaneye başvurmuş ve acil serviste pnömoni tedeavisi altında giderek bozulan klinik tablo sonrasında kardiyak arrest sonrası inotropik destek başlanmış, acilde hastayı değerlendirmemiz sonrasında sepsis ön tanısıyla yoğun bakıma alınmış. Yoğun bakımda yapılan TTE değerlendirmesinde apikal 4-boşluk görüntüsünde hiperkinetik ventriküller, subkostal pencerede inferior vena kava (IVC) çapının 1,46 cm olup düşük bulunması ve IVC kollapsibilite indeksinin \%50'nin üzerinde olması Sıvı açığını işaret etmesi nedeniyle hastaya hızlı bir şekilde sıvı infüzyonuna geçilmiş ve inotropik destek kesilmiştir. Hastaya bir saat içinde santral kateterizasyon yapılıp ölçülen santral venöz basınç $8 \mathrm{cmHO}_{2}$ olarak bulunmuştur ve hastanın hipotansiyonu düzelmiştir. Hastanın takibinde yapılan tetkiklerde akut miyelositik lösemi tanısı konmuş, 
ancak hastada bütün destek ve spesifik tedavilere rağmen takibinin 45inci gününde eksitus olmuştur.

Vaka 2: 49 yaşında erkek bilinen $\mathrm{KOAH}$, konjestif kalp yetersizliği ve iki yı önce geçirilmiş mitral kapak replasmanı operasyonu olan hasta nefes darlığı ve karın ağrısı şikayetleriyle hastanemize başvurmuş ve acilde takibi sırasında kardiyak arrest gelişmiş. Hastaya resüsitasyon sonrası hızlı sıvı yüklemesi ve inotropik destek tedavisi başlanıp yoğun bakımımıza gönderilmiş. Hastaya yoğun bakımda yapılan TTE görüntülemesinde fonksiyonel protez mitral kapak, kalp boşluklarının ileri derecede genişlemiş olduğu (Resim 1) ve tüm duvar hareketlerinin çok az olduğu gözlenmiş, modifiye Simpson yöntemiyle ejeksiyon fraksiyonu \%25 olarak ölçülmüştür. Hastanın sıvı yüklemesi azaltııp inotropik destek devam edilmiştir.

Vaka 3: 78 yaşında daha önceden immobil erkek hasta solunum sıkıntısıyla acile başvurmuş ve D-dimer yüksekliği ile torakal BT'de nonspesifik bulgularla pulmoner emboli olabileceği düşünülen bir klinik tablo ile entübe edilerek

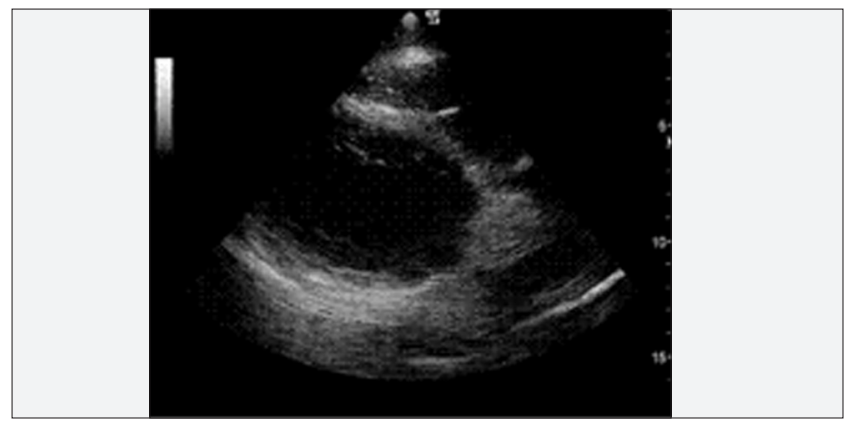

Resim 1. Vaka 2'nin parasternal uzun aks görüntüsünde kalp boşluklarının ileri derecede genişlemiş olduğu gözlenmektedir

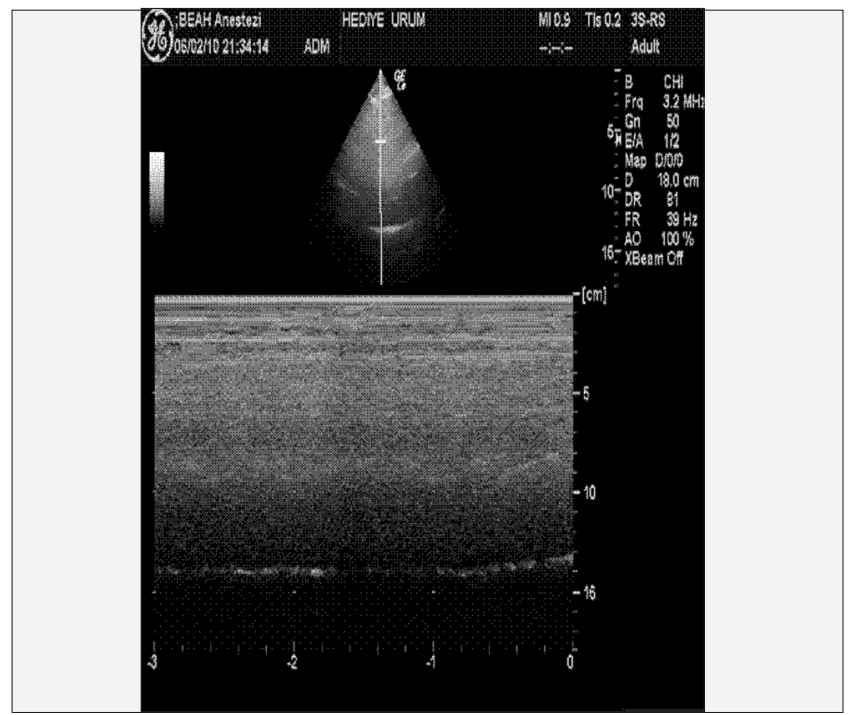

Resim 2. Vaka 5'in akciğer ultrason görüntüsünde M-modda normal "deniz ve kumsal" imajı görülmekte solunum desteğine alınmış ve düşük moleküler ağırlıklı heparin tedavisi başlanmış. Yoğun bakıma alınan hastaya definitif tanı için BT anjiografi yapılmak istenmiş, ancak serum kreatinin değeri yüksek (1,9 mg/dl) olması nedeniyle çekilemeyeceğinden derhal TTE yapılmış ve sağ atrium ve ventrikül boyutu normal, triküspid kapak normal, ancak global duvar hareketleri hipokinetik (EF:\%40) bulunmuştur. Plevral pencerede ise bilateral belirgin plevral efüzyon görülmüştür. Bu bulgularla pulmoner emboli ön tanısından uzaklaşılarak hastaya konjestif kalp yetersizliği nedeniyle inotrop ve diüretik başlanıp sıvı kısıtlaması yapılmıştır. Hasta beşinci günde ekstübe edilmiş ve TTE kontrolünde EF: \%46 olduğu ve plevral efüzyonun azaldığı gözlenmiştir. Yedinci günde de inotropik destek azaltılarak hasta kardiyoloji servisine gönderilmiştir.

Vaka 4: Pnömoni öntanısıyla interne edilen hasta acil serviste birkaç gündür takipteyken gelişen hipotansiyon için sıvı yüklemesi yapılırken oksijenasyonunun giderek bozulduğu ve hipotansiyonunun düzelmediği görülünce yoğun bakıma çekilmiş, burada kateter takılıp santral venöz basınç $17 \mathrm{cmHO}_{2}$ ölçülmüş ve TTE yapılmıştır. Septal ve apikal duvar hareketleri hipokinetik bulunarak, sepsis/ARDS tanısıyla hastaya inotropik tedavi ile sıvı kısıtlaması ve hemodiafiltrasyon başlanmıştır.

Vaka 5: 83 yaşında bayan hasta kalça protez operasyonu sonrası gastrointestinal (GIS) kanama ve solunum sıkıntısı nedeniyle entübe edilerek yoğun bakımda mekanik ventilasyon desteğine alınmış. Ancak satürasyonlarının düzelmemesi üzerine akciğer grafisi planlanmış fakat skopi cihazındaki bir arıza nedeniyle akciğerler ultrasonla TTE dışında detaylı olarak görüntülenmiştir. TTE'de kardiyak bir patoloji görülmeyip EF: \%55 bulunmuştur ve plevral pencerelerde bilateral minimal plevral efüzyon belirlenmiştir. Detaylı akciğer ultrasonu BLUE protokolüne (7) göre yapılmıştır. Prob üç zonda (her iki hemitoraksta midklaviküler hatta, midaksiller hatta ve posteriorda da vertebra ve skapula arasında) tüm interkostal aralıklardan görüntü almak üzere toraksta gezdirilmiştir. Hiçbir zonda pnömotoraksa ait tipik Mmodda "sea but not sands" görüntüsü ("deniz var kum yok") (8) alınmamış (Resim 2) ve pnömotoraks ekarte edilip yüksek PEEP uygulayarak atelektaziler açılmıştır.

\section{Tartışma}

Bu çalışmada görüldüğü üzere TTE \%94,3 oranda yeterli ve değerli değerlendirme verisi sağlayan bir araçtır, dolayısıyla transtorasik ekokardiyografi yoğun bakımda kritik hastaların takip ve tedavisinde etkin bir monitorizasyon aracı olarak kullanılabilecektir. Önceleri ekokardiografi yoğun 
Türk Yoğun Bakım Derneği Dergisi / Journal of the Turkish Society of Intensive Care 2012;10: 13-9

bakımda sadece tanısal amaçla kullanımaktaydı, ancak son on yılda özellikle transtorasik ekokardiyografi acilde ve yoğun bakımlarda kritik hastanın monitorizasyonunda ve hemodinamik değerlendirmesinde kullanılmaya başlanmıştır $(3,4,6,9)$. Ancak burada şunu açıkça ifade etmek gerekir ki, FATE protokolüne göre hastanın ekokardiyografi ile hızlı ve hedefe yönelik kabaca değerlendirilmesi bir kardiyolog tarafından yapılan ekokardiyografik görüntüleme ile karıştırılmamalıdır. Zira kalbin boşluklarının ve kontraktilitesinin hızlı ve kabaca değerlendirilmesi ile kaba bir kardiyak ön- ve ardyük değerlendirmesinde kapsamlı bir kardiyolojik değerlendirmenin gerektirdiği imaj kalitesine intiyaç yoktur. Nitekim hastalardan aldığımız görüntülerin hastalara ait yorumlarımız açısından güvenilirliği ve etkinliği yönünde görüntü kalitesi adına kardiyolog değerlendirmesi beş basamaklı bir skorlamayla tüm hastalarda iyi ve orta kaliteli görüntü olarak nitelendirilmiş ve hiçbir hastada değerlendirilemez boyutunda bulunmamıştır. Dolayısıyla ekokardiyografi, bu konuda kısa ve hedefe yönelik bir eğitim almış kardiyolog dışında uygulayıcı hekimler (yoğun bakım ve acil hekimleri gibi) tarafından da optimal görüntü kalitesiyle hastaların takip ve tedavisinde etkin bir şekilde kullanılabilir.

Önyükün geleneksel ölçütleri olan santral venöz basınç (CVP) ve pulmoner arter basıncı (PAP) ölçümlerinin sıvı cevabını belirlemede güvenilir olmadığı bilinmektedir (10). Ekokardiyografi invazif monitorizasyona alternatif olarak düşünülmüş ve özellikle septik şokta sıvı tedavisinde nabız basıncı varyasyonuna (PPV) korele sonografik bulgular belirlenmeye çalışılmıştır (11). Sıvı cevabını değerlendirmede en yararlı ekokardiyografik parametreler vena kava çapında solunumsal varyasyon ve atım hacmi (stroke volume) olarak görülmektedir (11). Septik şok hastalarında sıvı cevabı ile IVC çapında solunumsal değişiklikler arasında pozitif bir korelasyon bulunmuş, sıvı bolusları öncesi ve sonrasında IVC çapı değişiklikleri ve kardiyak debide artış arasında da belirgin ilişki saptanmıştır $(12,13)$.

Pershad ve ark., pediatrik hastalarda acil hekiminin sol ventrikül fonksiyonu ve önyükün indirek bir göstergesi olan inferior vena kava volumünün ölçümünde kaliteli ve doğru görüntü alabileceğini ileriye dönük gözleme dayalı bir çalışmayla göstermişlerdir (14). Benzer bir şekilde Moore ve ark.'da yaptıkları ileriye dönük çalışmada hipotansif hastalarda acil hekimlerinin ekokardiyografi ile sol ventrikül fonksiyonlarını değerlendirebileceklerini göstermişlerdir (15).

Çalışmamızda TTE değerlendirmesi bütün akustik pencerelerden yapılabilmiş ve sadece bir hastada yetersiz ve değersiz katkı sağlamıştır, bu da literatürle uyum göstermektedir. Yoğun bakımda TTE değerlendirmesi yapılan 469 vakalık büyük bir seride (16) bu oran \%0.4, 137'si ventilatör desteğinde olmak üzere 210 hastanın değerlendirildiği başka bir çalışmada (6) da \%2,6 olarak bulunmuştur. Bizim çalışmamızda da bütün TTE değerlendirmeleri mekanik ventilasyon altında yapılmıştır. Ventilasyon tedavisi, özellikle yüksek pozitif ekspirasyon sonu basınç (PEEP) uygulaması, yoğun bakım hastasında TTE görüntülemesinde sınırlı ve yetersiz akustik pencere nedenlerinden biridir. Bu konudaki eski pek çok literatürde yoğun bakım hastalarında bu nedenle TTE'nin yeterli olmayacağı yönünde bildiriler mevcuttu $(17,18)$, ancak görüntüleme teknolojisindeki gelişmelerle hastalar artık TTE ile optimal koşullarda değerlendirilebilmektedir $(19,20)$. Klinik açıdan sakıncası yoksa görüntüleme esnasında PEEP'i azaltmak da akustik pencereye katkıda bulunabilir (21). Bizim çalışmamızda mekanik ventilasyona rağmen TTE görüntü kalitesi bozulmamıştır, ancak çalışmamızın bu konudaki tek kısıtlılığı yeterince büyük bir çalışma grubumuzun olmamasıdır. Bunu bir sonraki çalışmamızda göz önüne almayı planlamaktayız.

Yoğun bakım hastaları da çoğu kez hemodinamik açıdan anstabil olup inotropik destek tedavisi gerektirirler, ancak bu hastalarda sıvı tedavisi mi yoksa inotropik desteğin azaltılması ya da arttırılması mı gerekir bunların belirlenmesi önemlidir. Ventriküler ölçümler ve duvar kalınlıklarıyla ön- ve ardyükün ekokardiyografik görüntülemesi sıvı dengesine rasyonel yaklaşımın belirlenmesini sağlar. Nitekim örnek ilk vakamızda kardiyak arrest sonrası sepsis ön tanısıyla acilden yoğun bakıma aldığımız hastaya hipotansiyon nedeniyle acilde başlanmış inotropik destek, ekokardiyografik değerlendirmede kontraktilitenin normal olup Sıvı açı̆̆ı belirlenmesi üzerine tedavisi değiştirilmiş ve sıvı yüklemesi yapılmıştır. Yetersizlikteki kalpte sistolik sol ventriküler fonksiyon normalse bozulmuş diastolik fonksiyon olasılığına dikkat etmek gerekir. Böyle durumlarda inotropik tedaviyi arttırmak problemi çözmez, önyükü düzeltmek gerekir. Çalışmamızda ekokardiyografi öncesinde 11 hastaya inotropik destek tedavi başlanmıştı, TTE inceleme sonrasında bunlardan birinin inotropları kesilirken 5 hastaya da inotrop tedavi başlanmıştır. Örneğin, dördüncü vakada, duvar hareketlerinde bozukluk olan ARDS vakasında, sIVI tedavisi değiştirilip inotropik tedaviye geçilmiştir. Íkinci vakada ise akut kolanjit tablosuyla gelen hasta CPR sonrası değerlendirilmiş ve sol kalp boşluklarında dilatasyon ve duvar hareketleri ileri derecede azalmış bulunduğundan sıvı yüklemesi durdurulup inotropik desteğe devam edilmiştir.

Son vaka ise akciğer ultrasonografisine bir örnek olabilir. Son zamanlarda akciğer ultrasonu ventile edilen kritik hastada akciğerin durumunu değerlendirmede kullanılabilen yeni bir araç olmuştur (22). Pnömotoraks, akciğer konsolidasyonu, alveolar-interstisyel sendrom ve plevral efuzyon gibi patolojilerin belirlenmesinde ve takibinde 
akciğer ultrasonunun önemine dair literatürler giderek artmaktadır (23-25). Normalde ultrason dalgaları gazla dolu anatomik yapılardan geçmez ve plevra haricinde akciğer parankimi ultrasonda görüntülenemez. Solunum esnasında viseral plevranın hareketiyle sallanan hiperekoik bir çizgi görülür ki buna plevral çizgi denir. Bu plevral çizginin ötesinde belirli aralıklarla tekrarlayan artefaktlar halinde yatay çizgiler görünür ve bunlara da A çizgileri denir. Bunun yanında özellikle akciğerin dependan bölgelerinde de B çizgileri denen izole vertikal çizgiler görülür. Bütün bu normal bulgular $\mathrm{M}$-modda da "deniz ve kumsal bulgusu (seashore sign)" denen görüntüye neden olur $(22,25)$.

Beşinci vakamızda akut periferik oksijen satürasyonu düşüşü nedeniyle hasta ventilasyon desteğine alınmış, ancak satürasyonu yükselmeyen hastanın portabl skopi cihazının bozuk olması nedeniyle akciğer patolojisinin belirlenmesi adına transtorasik ekokardiyografi ve akciğer ultrasonu yapılmışıır. TTE'de hastanın belirgin bir patolojisi olmadığı görülmüştür ve hasta akciğer yönünden değerlendirilmek üzere TTE'deki plevral pencere görüntüsüne ek olarak daha detaylı araştırımak üzere üç ayrı zondan daha görüntülenmiştir. Hiçbir zonda pnömotoraks görüntüsü alınmamış ve hastaya uygulanan PEEP arttırılarak atelektazik alanlar açılış ve satürasyonu bir saat içinde artmıştır.

Vakalarla örneklemek istediğimiz bulgularımı açıkça göstermektedir ki, transtorasik ekokardiyografi ve gereğinde akciğer ultrasonografisi bu kısaltılmış ve hızı protokollerle hemodinamik bozukluğu belirleyerek tedaviyi yönlendirip izlemeye olanak sağlar. Vakalarımızın \%38.8'inde mevcut bilgileri destekleyen bulguların ötesine gitmese de TTE değerlendirmesiyle doğrulanmış bilginin en az yeni bilgi kadar değerli olduğu kanısındayız.

Sonuç olarak; görülmektedir ki ultrasonografi yoğun bakımda yatakbaşı monitorizasyonda etkin bir şekilde kullanılabilecek noninvazif bir araçtır. Bu konuda hedefe yönelik bir eğitim ve kısa bir öğrenme eğrisi ile yoğun bakım hekimleri de günlük pratiklerinde hasta takibinde optimal görüntü kalitesiyle transtorasik ekokardiyografi ve akciğer ultrasonunu uygulayabileceklerdir.

\section{Kaynaklar}

1. Beaulieu Y, Marik PE. Bedside ultrasonography in the ICU, Part 1. Chest 2005;128:881-95.

2. Beaulieu Y, Marik PE. Bedside ultrasonography in the ICU, Part 2. Chest 2005;128:1766-81.

3. Cholley BP, Vieillard-Baron A, Mebazaa A. Echocardiography in the ICU: time for widespread use! Intensive Care Med 2006;32:9-10

4. Price S, Nicol E, Gibson DG, Evans TW. Echocardiography in the critically ill: current and potential roles. Intensive Care Med 2006;32:48-59.

5. Jensen MB, Sloth E. Echocardiography for cardiopulmonary optimization in the intensive care unit: should we expand its use? Acta Anaesthesiol Scand 2004;48:1069-70.
6. Jensen MB, Sloth E, Larsen KM, Schmidt MB. Transthoracic echocardiography for cardiopulmonary monitoring in intensive care. Eur J Anaesthesiol 2004;2:700-7.

7. Liechtenstein D, Meziere G. Relevance of lung ultrasound in the diagnosis of acute respiratory failure. The BLUE-protocol. Chest 2008; 134:117-25.

8. Targhetta R, Bourgeosis JM, Chavagneux R, Coste E, Amy D, Balmes $\mathrm{P}$, et al. Ultrasonic signs of pneumothorax:preliminary work. J Clin Ultrasound 1993;21:245-50.

9. Rose JS. Ultrasound in clinical trauma. Emerg Med Clin North Am 2004:22:581-99.

10. Michard F, Teboul JL. Predicting fluid responsiveness in ICU patients: a critical analysis of the evidence. 2 Chest 2002;121:2000-8.

11. Charron C, Caille V, Jardin F, Vieillard-Baron A. Echocardiographic measurement of fluid responsiveness. Curr Opin Crit Care 2006;12:249-54.

12. Feissel M, Michard F, Faller JP, Teboul JL. The respiratory variation in inferior vena cava diameter as a guide to fluid therapy. Intensive Care Med 2004;30:1834-7.

13. Barbier C, Loubières Y, Schmit C, Hayon J, Ricôme JL, Jardin F, et al. Respiratory changes in inferior vena cava diameter are helpful in predicting fluid responsiveness in ventilated septic patients. Intensive Care Med 2004;30:1740-6.

14. Pershad J, Myers S, Plouman C, Rosson C, Elam K, Wan J, et al. Bedside Limited Echocardiography by the Emergency Physician Is Accurate During Evaluation of the Critically III Patient. Pediatrics 2004;114:e667-71.

15. Moore CL, Rose GA, Tayal VS, Sullivan DM, Arrowood JA, Kline JA. Determination of left ventricular function by emergency physician echocardiography of hypotensive patients. Acad Emerg Med 2002;9:186-93.

16. Bossone E, DiGiovine B, Watts $S$, et al. Range and prevalence of cardiac abnormalities in patients hospitalized in a medical ICU. Chest 2002;122:1370-6.

17. Hwang JJ, Shyu KG, Chen JJ, Tseng YZ, Kuan P, Lien WP. Usefulness of transesophageal echocardiography in the treatment of critically ill patients. Chest 1993;104:861-6.

18. Khoury AF, Afridi I, Quinones MA, Zoghbi WA. Transesophageal echocardiography in critically ill patients: feasibility, safety and impact on management. Am Heart J 1994;127:1363-71.

19. Vignon $P$, Chastagner $C$, François B, Martaillé JF, Normand $S$, Bonnivard $M$, et al. Diagnostic ability of hand-held echocardiography in ventilated critically ill patients. Crit Care 2003; 7:R84-91

20. Joseph MX, Disney PJS, Da Costa R, Hutchison SJ. Transthoracic echocardiography to identify or exclude cardiac cause of shock. Chest 2004;126:1592-7.

21. Vignon $P$, Mentec $H$, Terré $S$, Gastinne $H$, Guéret $P$, Lemaire $F$. Diagnostic accuracy and therapeutic impact of transthoracic and transesophageal echocardiography in mechanically ventilated patients in the ICU. Chest 1994;106:1829-34.

22. Bouhemad B, Zhang M, Lu Q, RoubyJJ. Clinical review. Bedside lung ultrasound in critical care practice. Crit Care 2007;11:205.

23. Agricola E, Bove T, Oppizzi M, Marino G, Zangrillo A, Margonato A, et al. "Ultrasound Comet-Tail Images": A Marker Of Pulmonary Edema: A Comparative Study With Wedge Pressure And Extravascular Lung Water. Chest 2005;127:1690-95.

24. Bedetti G, Gargani L, Corbisiero A, Frassi F, Poggianti E, Mottola G. Evaluation of ultrasound lung comets by hand-held echocardiography. Cardiovasc Ultrasound 2006; 31;4:34.

25. Zhang M, Liu ZH, Yang JX, Gan JX, Xu SW, You XD, et al. Rapid detection of pneumothorax by ultrasonography in patients with multiple trauma. Crit Care 2006;10:R112. 